\title{
Maternal age and origin of non-disjunction in trisomy $21^{*}$
}

\author{
J F MATTEI, S AYME $\dagger, M$ G MATTEI + AND F GIRAUD
}

From the Centre de Génétique Médicale, Hôpital d'Enfants de la Timone, F-13385 Marseille Cedex 4, Francẹ:

SUMMARY The role of maternal age in chromosomal non-disjunction was investigated by studying 51 families in whom the origin of the meiotic anomaly had been identified. Results of this studyj were compared with previously published data. This comparison did not show any difference iner mean maternal age, nor in distribution of maternal ages when the origin of non-disjunction wasi maternal, or paternal, or occurred at the first or second meiotic division. These results make questionable the role of maternal age in the birth of Down's syndrome children.

The increased risk of older women giving birth to a child with trisomy 21 has been known for many years. ${ }^{1}$ Penrose and Smith $^{2}$ in their analysis of published reports concluded that there were two maternal age distributions: "one in which the maternal age is not a significant factor, and the other in which the maternal age is a fundamental influence". These comments were based on the observed livebirth incidence of trisomy 21 . Until recently the majority of studies in this field have been based on similar birth data. ${ }^{3}$

With the advent of quinacrine fluorescence techniques, many chromosome variants have been revealed, allowing workers to evaluate parental and meiotic origin of individual chromosomes. ${ }^{4-12}$

The aim of this report was to study the origin of non-disjunction as a function of parental age using data from previous publications and our own results.

\section{Material and methods}

Seventy consecutive cases of trisomy 21 and their parents, referred to us from August 1977 to December 1978, were examined cytogenetically. These cases came from a large region, but mainly (52/70) from the department of Bouches-du-Rhône. During the same period, 28255 liveborn children were reported by the Regional Public Health Service for the same department. The incidence of trisomy 21

*Supported by grants from INSERM (ATP No 37.70.69)

†Attachée de Recherche à l'INSERM

¥Attachée de Recherche au CNRS

Received for publication 19 November 1979 can be estimated at $0 \cdot 184 \%$ and it was thought thato these cases represent all cases of trisomy 21 bornduring this period. Thus, in these cases $(74.28 \%)$ the results presented are not based on biased as-o certainment. However, it cannot be confirmed that the other cases outside this department $(25 \cdot 72 \%)$ represent all the cases in the region.

Slides were stained with quinacrine mustard ando the structural variants were scored as described previously. ${ }^{12}$ Fifty mitoses were analysed in alle parents; the karyotypes were consistently normal and in particular no parental mosaics were observed.

In 51 of the families two independent observerso agreed as to the origin of the supernumerary chromosome 21 . In the other 19 families the two observers disagreed in six cases, and in 13 cases they agreed: that assignment of chromosomal origin was im- 3 possible.

Four groups were identified according to the parental (maternal or paternal) and meiotic (first or second division) origin of the non-disjunction. Since age distributions did not follow a normal curve, statistical comparison of the different groups was made using Wilcoxon's test and the $\chi^{2}$ test. For theor latter test we compared maternal ages by scoring 0 ages as follows: $<30$ years and $\geqslant 30$ years; $<35$ andN $\geqslant 35 ;<38$ and $\geqslant 38 ;<40$ and $\geqslant 40$. This is in ${ }_{\sigma}^{\omega}$ agreement with the hypothesis that two maternal age distributions exist. ${ }^{2}$ Fathers were divided into two groups according to age, $<40$ years and $\geqslant 40 œ$ years old, as proposed by Erickson. ${ }^{13}$

Maternal age distribution in the general popu-ōं lation was based on census data on maternal age at time of birth from August 1977 to December $1978 \stackrel{\widetilde{D}}{\frac{\Omega}{2}}$ 
in the Bouches-du-Rhône department (28 255 live births). In this population the mean maternal age was $26 \cdot 3$ years.

\section{Results}

Informative results were obtained in 51 families and are shown in table $1 \mathrm{a}$ and $\mathrm{b}$ according to paternal and maternal age and as a function of the parental and meiotic origin of non-disjunction. The parental ages of the 19 other families are shown in table 2.

The mean ages of the mothers and fathers of the informative and non-informative families do not differ significantly, neither do the age distributions. Thus the 51 families studied are representative of the 70 original families in terms of parental age.

Although to our knowledge the present study is the largest published one of its kind, the number of

TABLE 1a Cases of maternal non-disjunction: mean age of parents

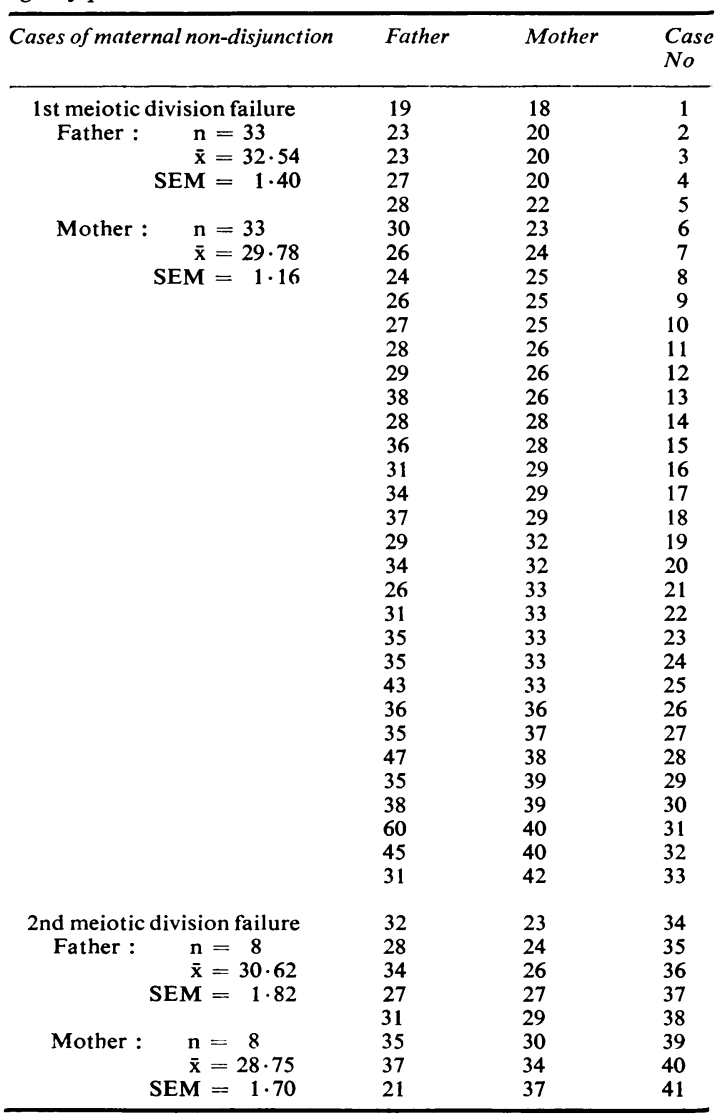

TABLE $1 \mathrm{~b}$ Cases of paternal non-disjunction: mean age of parents

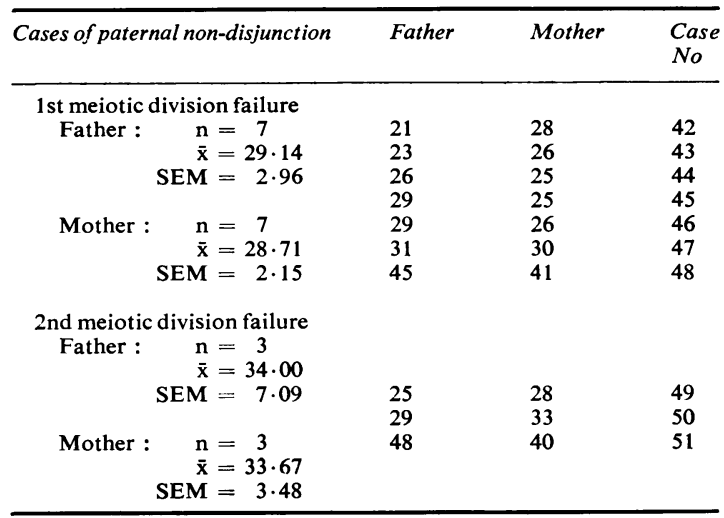

TABLE 2 Cases where the origin of the supernumerary chromosome is not known

\begin{tabular}{|c|c|c|}
\hline & Age of father & Age of mother \\
\hline $\begin{array}{l}\text { Families where } \\
\text { observers disagreed } \\
\quad n=6\end{array}$ & $\begin{array}{l}44 \\
32 \\
36 \\
43 \\
28 \\
34\end{array}$ & $\begin{array}{l}30 \\
37 \\
31 \\
42 \\
21 \\
29\end{array}$ \\
\hline $\begin{array}{l}\text { Inconclusive } \\
\text { families } \\
n=13\end{array}$ & $\begin{array}{l}34 \\
42 \\
28 \\
29 \\
24 \\
36 \\
24 \\
51 \\
34 \\
31 \\
54 \\
19 \\
24\end{array}$ & $\begin{array}{l}37 \\
29 \\
27 \\
25 \\
22 \\
24 \\
24 \\
37 \\
33 \\
31 \\
38 \\
17 \\
23\end{array}$ \\
\hline & $\begin{array}{r}34 \cdot 05 \\
2 \cdot 15\end{array}$ & $=\begin{array}{r}29.32 \\
1.56\end{array}$ \\
\hline
\end{tabular}

persons in certain groups is rather small. Accordingly, we combined our results with those reported by Magenis et al ${ }^{10}$ and Hansson and Mikkelsen ${ }^{11}$ in order to yield more valid statistical analyses.

Regardless of whether non-disjunction is of paternal or maternal origin, there is a shift in the age distribution of mothers of trisomy 21 children with respect to the general population. There is an excess of older mothers at the birth of affected offspring (table 3 ; fig 1 ).

There was no significant difference between the maternal ages in groups where non-disjunction was of either paternal or maternal origin (table 4, 5). 
TABLE 3 Distribution of maternal ages in data compiled from Magenis et al, ${ }^{10}$ Hansson and Mikkelsen, ${ }^{11}$ and the present study

\begin{tabular}{|c|c|c|c|c|c|c|c|}
\hline & \multicolumn{7}{|c|}{ Distribution of maternal age } \\
\hline & $\leqslant 19$ & $20-24$ & $25-29$ & $30-34$ & $35-39$ & $40-44$ & $>45$ \\
\hline $\begin{array}{l}\text { Maternal origin of non-disjunction } n=80 \\
\text { Paternal origin of non-disjunction } n=24 \\
\text { General population } n=28255 \\
\quad \text { (mean maternal age } 26.3 \text { years) }\end{array}$ & $\begin{array}{l}2 \cdot 5 \% \\
0 \\
5 \cdot 7 \%\end{array}$ & $\begin{array}{l}22 \cdot 5 \% \\
25 \cdot 0 \% \\
32 \cdot 7 \%\end{array}$ & $\begin{array}{l}30 \cdot 00 \% \\
37.5 \% \\
37.9 \%\end{array}$ & $\begin{array}{l}23 \cdot 75 \% \\
16 \cdot 66 \% \\
17 \cdot 4 \%\end{array}$ & $\begin{array}{l}10 \cdot 00 \% \\
8 \cdot 33 \% \\
4.9 \%\end{array}$ & $\begin{array}{l}10 \cdot 00 \% \\
12.5 \% \\
1.3 \%\end{array}$ & $\begin{array}{l}1 \cdot 25 \% \\
0 \\
0 \cdot 1 \%\end{array}$ \\
\hline
\end{tabular}
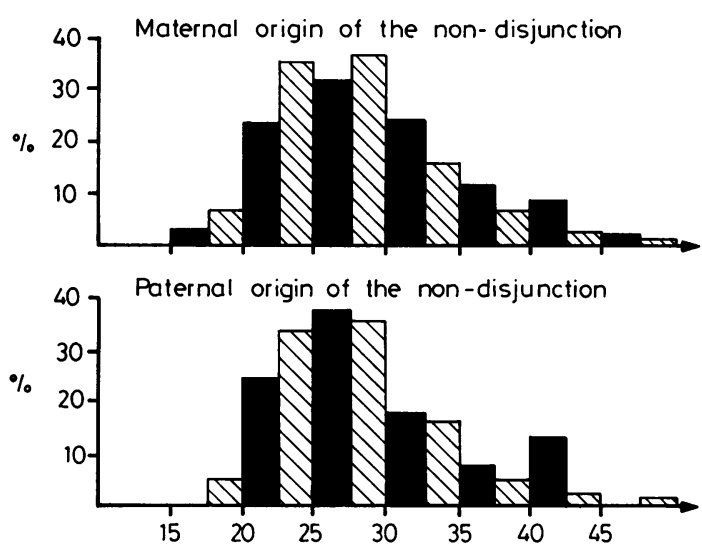

Age of mothers

Mothers of trisomy 21 children

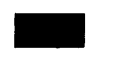

General population

FIGURE Distribution of maternal age according to the origin of the non-disjunction.

TABLE 4 Expected and observed number of mothers according to age group and origin of non-disjunction

\begin{tabular}{|c|c|c|c|c|}
\hline \multirow[t]{2}{*}{ Mothers'age } & \multicolumn{2}{|c|}{ Maternal non-disjunction } & \multicolumn{2}{|c|}{ Paternal non-disjunction } \\
\hline & Observed & Expected & Observed & Expected \\
\hline$<30$ & 44 & $45 \cdot 38$ & 15 & $13 \cdot 62$ \\
\hline$\geqslant 30$ & 36 & $34 \cdot 62$ & 9 & $10 \cdot 38$ \\
\hline$<35$ & 63 & 63.07 & 19 & $18 \cdot 93$ \\
\hline$\geqslant 35$ & 17 & $16 \cdot 93$ & 5 & 5.07 \\
\hline$<38$ & 67 & $66 \cdot 15$ & 19 & $19 \cdot 85$ \\
\hline$\geqslant 38$ & 13 & $13 \cdot 85$ & 5 & $4 \cdot 15$ \\
\hline$<40$ & 71 & $70 \cdot 76$ & 21 & $21 \cdot 24$ \\
\hline$\geqslant 40$ & 9 & $9 \cdot 24$ & 3 & $2 \cdot 76$ \\
\hline
\end{tabular}

When paternal age was used as a basis for com- $\overrightarrow{0}$ parison, we found no significant difference either $\vec{\omega}$ (table 6).

Maternal age did not vary significantly when the stage of meiotic failure was examined, that is, there. was no maternal age difference between first and $\vec{v}$ second division meiotic failure (table 7).

Identical results (no significant difference) were obtained when maternal age ranks were compared ${ }_{\circ}^{\infty}$ as a function of the origin of non-disjunction using Wilcoxon's test, regardless of the arbitrarily chosen cut-off age.

In other words, although the distribution of ages of mothers at the birth of a child with trisomy 21 is

TABLE 6 Expected and observed number of fathers according to age group and origin of the non-disjunction

\begin{tabular}{llllll}
\hline Fathers'age & \multicolumn{2}{l}{ Maternal non-disjunction } & \multicolumn{2}{c}{ Paternal non-disjunction } \\
\cline { 2 - 3 } \cline { 5 - 6 } & Observed & Expected & & Observed & Expected \\
\hline$<40$ & 69 & $68 \cdot 4$ & 20 & $20 \cdot 6$ \\
$\geqslant 40$ & 11 & 11.6 & 4 & 3.4 \\
\hline
\end{tabular}

TABLE 7 Expected and observed number of mothers according to age group and meiotic failure

\begin{tabular}{|c|c|c|c|c|}
\hline \multirow[t]{3}{*}{ Mothers'age } & \multicolumn{4}{|c|}{ Origin of non-disiunction } \\
\hline & \multicolumn{2}{|c|}{ Maternal } & \multicolumn{2}{|l|}{ Paternal } \\
\hline & $\begin{array}{l}\text { lst } \\
\text { division }\end{array}$ & $\begin{array}{l}2 n d \\
\text { division }\end{array}$ & $\begin{array}{l}\text { Ist } \\
\text { division }\end{array}$ & $\begin{array}{l}\text { 2nd } \\
\text { division }\end{array}$ \\
\hline$<38$ & $\begin{array}{l}53 \\
(54 \cdot 4)\end{array}$ & 14 & 11 & 8 \\
\hline$\geqslant 38$ & $\begin{array}{l}12 \\
(10 \cdot 6)\end{array}$ & $\begin{array}{c}1 \\
(2.4)\end{array}$ & $\begin{array}{c}4 \\
(3 \cdot 2)\end{array}$ & $\begin{array}{l}1 \\
(1 \cdot 8)\end{array}$ \\
\hline
\end{tabular}

TABLE 5 Statistical study with data compiled from Magenis et al, ${ }^{10}$ Hansson and Mikkelsen, ${ }^{11}$ and the present study

\begin{tabular}{|c|c|c|c|c|}
\hline & \multicolumn{4}{|l|}{ Meiotic origin } \\
\hline & \multicolumn{2}{|l|}{ Ist division } & \multicolumn{2}{|l|}{ 2nd division } \\
\hline & Father & Mother & Father & Mother \\
\hline Paternal origin & $\begin{aligned} \mathbf{n} & =15 \\
\overline{\mathbf{x}} & =29.66 \\
\text { SEM } & =1.85\end{aligned}$ & $\begin{aligned} \mathbf{n} & =15 \\
\overline{\mathbf{x}} & =28.93 \\
\text { SEM } & =1.93\end{aligned}$ & $\begin{aligned} \mathbf{n} & =9 \\
\overline{\mathbf{x}} & =30.44 \\
\mathrm{SEM} & =2.32\end{aligned}$ & $\begin{aligned} \mathbf{n} & =9 \\
\overline{\mathbf{x}} & =29.55 \\
\text { SEM } & =1.79\end{aligned}$ \\
\hline
\end{tabular}


different from the distribution of ages of mothers at the birth of normal children, this difference exists whether or not non-disjunction occurred in the mother, both in our data and in previously reported data.

\section{Discussion}

Our data are consistent with the null hypothesis that there is no difference in mean maternal age among the four groups of origin. It is possible that such a conclusion could be false because of a type 2 error. The reasons for such a situation are twofold. Firstly, there is an absence of trisomy 21 children born to older mothers in our data which masks the effect of maternal age. In our sample $21.56 \%$ of mothers were above 35 years of age, versus $13.63 \%$ in the data of Hansson and Mikkelsen, ${ }^{11}$ and $25.8 \%$ in the data of Magenis et al. ${ }^{10}$ Our maternal age distribution does not differ from that of the data previously reported, and it is in agreement with published results showing that the maternal age of mothers of affected children is decreasing. ${ }^{14-19}$ Secondly, our sample is perhaps too small for the expected difference to be seen. If paternal origin of a supernumerary chromosome 21 is independent of maternal age, it would be expected that the distribution of maternal ages in this population would be the same as in the control population. Accordingly, the expected proportion of mothers above 35 years would be $6.3 \%$. In the data compiled, when the origin of non-disjunction was maternal, the proportion of mothers above 35 years was $21 \cdot 25 \%$. In view of this discrepancy it can be estimated that our sample size would have to be twice as large in order to show a difference of this magnitude, choosing a low type 2 error.

Nevertheless, the fact that we did not observe any difference in the present sample merits a few comments. Concerning cytogenetic investigations, the following point should be made. The origin of nondisjunction is determined as a function of chromosomal morphology and possible chromatid exchanges involving the short arms are not taken into account. Although the latter event occurs infrequently, ${ }^{20}$ its existence is a confirmed reality. ${ }^{21}{ }^{22}$ Finally, Langenbeck et $a^{23}$ and Jacobs and Morton ${ }^{24}$ underlined the presence of bias when studying the transmission of chromosome markers. Although such bias exists regarding the meiotic timing of non-disjunction, it does not interfere when comparing the effects of maternal age in mothers who are and are not at the origin of the defect.

A significant correlation between ages of husbands and wives is well known and is verified in the present study. If paternal age were shown to have an effect on the origin of non-disjunction, then it would be reasonable to expect that when non-disjunction is of paternal origin the mothers would be older than those in the general population simply because of the above correlation. However, this hypothetical situation assumes that the effect of paternal age is as intense as the effect of maternal age, but we know that this assumption is false. Even if paternal age is a factor involved, ${ }^{2526}$ its effect is certainly a weak one. In our study only one father was older than 54 years and in this case non-disjunction was not of paternal origin.

When comparing distributions of maternal ages where non-disjunction occurred during the first meiotic division and those where non-disjunction arose during the second division, no significant differences were found.

Consequently, it should be concluded that either both first and second division non-disjunction are equally affected by maternal age, or that both events are unrelated to age, and that some other factor could be responsible for the higher maternal age observed at the birth of children with trisomy 21 . These results lead to the necessity of requestioning the role attributed to ageing of the ovum during first meiotic prophase in women. Indeed, since the incidence of offspring with trisomy 21 is higher in older women it is conceivable that maternal ageing could act, not during meiosis, but after fertilisation, by preferentially allowing development of trisomy 21 embryos. One point in favour of this hypothesis is that in our series the age of mothers with affected children was significantly higher than that of mothers in the general population, whether or not the non-disjunction was of maternal origin. The existence of such factors, as proposed by Erickson et $a l,{ }^{13}$ suggests that the relationship between maternal age and the incidence of trisomy 21 results from biased ascertainment which does not take into account spontaneous abortions of trisomy 21 embryos. In this respect it is important to note that the age of mothers of children with Klinefelter's syndrome is greater than the maternal age in the general population, ${ }^{27}$ and paternal non-disjunction is involved in $39 \%$ of such cases. ${ }^{28}$ In order to verify this suggestion, the age of women who have an early spontaneous abortion of a trisomy 21 fetus and the age of mothers who give birth to children with trisomy 21 could be compared. One would expect to find a significantly lower age in the spontaneous abortion group if the hypothesis were proved valid. Data published by Boue et $a l^{29}$ and Creasy et $a l^{30}$ do not verify this hypothesis. However, studies of this type involve women in whom pregnancy is detected and thus cannot take into account cases of very early abortion. Finally, comparison of populations 
investigated at an interval of several years is difficult to perform because of the decrease in the mean maternal age and the presence of widespread contraception.

\section{References}

1 Fraser J, Mitchell A. Kalmuk idiocy: report of a case with autopsy with notes on sixty-two cases. $J$ Ment $S c i$ 1876;22:169.

2 Penrose LS, Smith GF. Down's anomaly. Boston: Little, Brown and Co, 1966.

${ }^{3}$ Giraud F, Mattei JF. Aspects épidémiologiques de la trisomie 21. Rapport aux Troisièmes Journées Européennes de Conseil Génétique, Genève, 25-27 Octobre 1974. J Genet Hum 1975;23, suppl 1:1-30.

${ }^{4}$ Licznerski G, Lindsten J. Trisomy 21 in man due to maternal non-disjunction during the first meiotic division. Hereditas 1972;70:153-4.

5 Robinson JA. Origin of extra chromosome in trisomy 21. Lancet 1973;i:131-3.

- Smith GF, Sachdeva S. Origin of extra chromosome in trisomy 21. Lancet $1973 ; \mathbf{i}: 487$.

7 Giraud F, Mattei JF, Mattei MG. Etude chromosomique chez les parents d'enfants trisomiques 21: chromosomes marqueurs, remaniements, cassures et aneuploïdies. Lyon Med 1975;233:241-51.

8 Mikkelsen M, Hallberg A, Poulsen H. Maternal and paternal origin of extra chromosome in trisomy 21. Hum Genet 1976;32:17-21.

- Wagenbichler P, Killian W, Rett A, Schnedl W. Origin of the extra chromosome no 21 in Down's syndrome. Hum Genet $1976 ; 38: 13-6$.

10 Magenis RE, Overton KM, Chamberlin J, Brady T, Lovrien E. Parental origin of the extra chromosome in Down's syndrome. Hum Genet 1977;37:7-16.

11 Hansson A, Mikkelsen M. The origin of the extra chromosome 21 in Down's syndrome. Cytogenet Cell Genet 1978; 20:194-203.

12 Mattei JF, Mattei MG, Ayme S, Giraud F. Origin of the extra chromosome in trisomy 21 . Hum Genet 1979;46: 107-10.

13 Erickson JD. Down syndrome, paternal age, maternal age and birth order. Ann Hum Genet 1978;41:289-98.

14 Uchida IA. Epidemiology of mongolism; the Manitoba study. Ann NY Acad Sci 1970;171:361-9.

15 Gardner RJM, Veale AMO, Parslow MI, A survey of 972 cytogenetically examined cases of Down syndrome. NZ Med J 1973 ;78:403-9.
16 Lindsjo A. Down's syndrome in Sweden. Acta Paediatr Scand 1974;63:571.

17 Lowry RB, Hones DC, Renwock DHG, Trimble BK. Down syndrome in British Columbia, 1952-1973. In- क? cidence and mean maternal age. Teratology 1976;14: 29-34.

18 Mikkelsen M, Fischer G, Stene J, Stene E, Peterson E. Incidence study of Down's syndrome in Copenhagen, 1960-1971 with chromosome investigation. Ann Hum $\triangle$ Genet 1976;40:177-82.

19 Evans JA, Hunter AGW, Hamerton JF. Down syndrome and recent demographic trends in Manitoba. $J$ Med Genet $\vec{\circ}$ $1978 ; 15: 43-7$.

20 Craig-Holmes AP, Moore FB, Shaw MW. Polymorphism $\overrightarrow{\vec{\omega}}$ of human C-band heterochromatin. II. Family studies with suggestive evidence for somatic crossing over. $\mathrm{Am} J$ Hum Genet 1975;27:178-89.

21 Nakagome $Y$, Kitagawa $T$, Iinuma $K$, Matsunaga $E$. Shinoda T, Ando T. Pitfalls in the use of chromosome $\mathcal{V}$ variants for paternity dispute cases. Hum Genet 1977; 37:255-60.

22 Robinson JA, Buckton KE, Evans HJ, Robson EB. A possible mutation of a fluorescence polymorphism. Ann 음 Hum Genet 1978;41:323-8.

${ }^{23}$ Langenbeck U, Hansmann I, Hinney B, Honig V. On the origin of the supernumerary chromosome in autosomal trisomies with special reference to Down's syndrome. $\overrightarrow{0}$ A bias in tracing non-disjunction by chromosomal and biochemical polymorphisms. Hum Genet 1976;33:89-102.

24 Jacobs PA, Morton NE. Origin of human trisomics and polyploids. Hum Hered 1977;27:59-79.

25 Stene J, Stene E. Statistical methods for detecting a moderate paternal age effect on incidence of disorder when a maternal one is present. Ann Hum Genet 1977;40:343-53.

26 Stene J, Stene E. On data and methods in investigations on parental age effects. Ann Hum Genet 1978;41:465-8.

27 Court Brown WM, Law P, Smith PG. Sex chromosome aneuploidy and parental age. Ann Hum Genet 1969;33: 1-14.

28 Edwards JH. On the distribution of phenotypes in XXY males and their parents. J Med Genet $1971 ; 8: 434-7$.

29 Boue J, Boue A, Lazar P. Retrospective and prospective epidemiological studies of 1500 karyotyped spontaneous human abortions. Teratology $1975 ; 12: 11-26$.

30 Creasy MR, Crolla JA, Alberman ED. A cytogenetic study of human spontaneous abortions using banding techniques. Hum Genet 1976;31 :177-96.

Requests for reprints to Dr J F Mattei, Service de Pediatrie et Génétique Médicale, Hôpital d'Enfants, 13385 Marseille Cedex 4, France. 